\title{
FETAL ORIGIN OF ADULT DISEASE
}

Nguyen Cong Khanh

\begin{abstract}
"Fetal origins of adult disease", often called the "Barker hypothesis" after a large proportion data of Barker and colleagues in Southampton over the last decade, that adverse influences early in development, and particularly during intrauterine life, can result in permanent changes in structure, physiology, metabolism, which result in increased disease risk in adulthood. Many further studies have provided evidence for the hypothesis that size at birth is related to the risk of developing disease in later life. In particular, links are well established between reduced birthweight and increased risk of coronary heart disease, diabetes, hypertension and stroke in adulthood. The most widely accepted mechanisms thought to underlie these relationship are those of altered fetal nutrition, genetic-epigenetic links, fetal programming and fetal excess glucocorticoid exposure. It is suggested that the fetus makes physiological adaption in response to changes in its environment to prepare itself for posnatal life. The "Fetal origin of adult disease" hypothesis is attractive. It suggests that these diseases could be prevented by improving maternal health and fetal development.
\end{abstract}

Key words: Development origin of adult disease, Chronic diseases, Heart disease, Hypertension, Diabetes, Programming.

1. FETAL ORIGIN OF ADULT DISEASE HYPOTHESIS

The "Fetal Origin of Adult Disease" hypothesis often called the "Barker hypothesis" after a large proportion of the data of Professor David Barker (1938-2013) and colleagues in Southampton over the last decades of the $20^{\text {th }}$ century states that adverse influences early in growth and developmental period, particularly during intrauterine life, can result in permanent changes in structure, physiology and metabolism, which result in increased disease risk in adulthood.

Since 1986, Barker and collesgues noted that the regions in England and Wales that the highest rates of malnutrition and infant mortality in the early $20^{\text {th }}$ century also had the highest rate of mortality from conorary heart disease in dacades later [1]. Two large studies of men in Shieffiel and Hertforshire from t989 to 1993 shwed a strong relationship between death from coronary heart disease and decreasing birthweight, head circumferencs or poderal index, It was particularly people who were born growth restricted rather than premature who were ar risk [2][3]. Barker showed that undernutrition during gestation was an important contributor to low birthweight, small size at birth and early origin of adult

Received: September $12^{\text {th }}, 2020$

Accepted: November $20^{\text {th }}, 2020$

Corresponding author: Prof.Dr. Nguyen Cong Khanh

Address:nguyen.congkhanh@yahoo.com.vn 
cardiac and metabolic disorders [4]. The fetus is dependent on the nutrients from the mother and adapts to an inadequate nutrient supply in a number of ways : prioritization of brain growth at the expense of other tissues such as the abdominal viscera; reduced secretion or sensitive to the fetal growth hormones as insulin and IGF-1; and up-regulation of the hypothalamuspituitary-adrenal (HPA) axis. Barker and al. proposed the "Thrifty phenotype" hypothesis; when the fetal environment is poor, there is an adaptive response, which optimizes the growth of key body organs to the detriment of others and leads to altered postnatal metabolism, which is designed to enhance postnatal survival under conditions of intermittent or poor nutrition [5]. The fetal has many homeostatic and homeorhetic mechanisms that confer immediate survival advantage e.g. alterations in regional blood flows and organ growth when nutrient or oxygen supply is reduced, even if there may be subsequent postnatal costs [6]. The fetal origin of adult disease (FOAD) hypothesis proposes that although occurring in response to a transient phenomen (fetal-undernutrition) these adaptions become permanent or "programmed" because they occur during critical periods of early development of the fetal [7][8]. Fetal life is a sensitive period of cellular proliferation and maturation, resulting in structural and functional changes in cells, tissues and organ systems. All organ systems undergo developmental programming in utero that predetermine subsequent physiologic and metabolic adaptions during adult life. These concepts have been referred to fetal origin of adult onset disease, also health and disease [9][10]. The origin of adult onset disease is the profound effects of "mismatch" between the early developmental environment and the subsequent environment in childhood and adult life [11].

The hypothesis is supported by examples in experimental animals of permanent structural and metabolic changes resulting from transient nutritional insults in utero. Maternal rats protein restriction in pregnancy leads to higher blood pressure, impaired glucose tolerance, insulin resistance and altered hepatic architecture and function in the offspring. Fetal undernutrition results in susceptivity to disease in later life, as reduced insulin sensitivity, low muscle mass, pancreatic beta cell mass and nephron numbers, altereial structure, and up-regulation of the HPA axis and sympathic nervous system [12][[13].

After the first studies of Barker and al., many other studies in various countries and regions note also that reduced birthweight and size at birth have been associated with an increased incidence of adult chronic disease in later life. Many diseases were well accepted association, with small birth size as hypertension, coronary heart disease, non-insulin dependant disorders, stroke, dislipidemia [14]; and some others were less well association with small birth size as chronic lung disease, depression, schizophrenia, breast cancer, testicular cancer [15]]16]. 
Table 1. Diseases linked with birthweight

\begin{tabular}{ll}
\hline Diseases & Reference \\
\hline Strong association with small birth size & \\
Hypertension & Huxley RR và cs, 2000 \\
Conorary heart disease & Barker DJ và cs, 1989 \\
Non insulin dependent diabetes & Newsome CA và cs, 2003 \\
Stroke & Roseboom JJ và cs, 2000 \\
Dislipidemia & Henry JA và cs, 1997 \\
Elevated clotting factors & Henry JA và cs, 1997 \\
Impaired neurodevelopment & McCartoon CM và cs, 1996 \\
Less association with small birth size & \\
Chronic lung disease & Lal MK và cs, 2003 \\
Depression & Gale CR và cs, 2004 \\
Schizophrenia & Kunugi H và cs, 2001 \\
Behavioural problems & Hack M và cs, 2004 \\
Left handedness & James WH, 2001 \\
Reduced uterine and ovarian size & Ibanez L. và cs, 2000 \\
Precocious pubarche & Ibanez L. và cs, 2000 \\
Breast cancer & Elias SG. và cs, 2004 \\
Testicular cancer & English PB và cs, 2003 \\
Described association with large birth size & \\
Polycystic ovaty disease & Cresswell JL. và cs, 1997 \\
Breast cancer & Michels KB. và cs, 1996 \\
Prostate cancer & Nilsen TI. và cs, 2005 \\
Testicular cancer & Hjaldrim LL. và cs, 2004 \\
Childhood leukemia & \\
\hline
\end{tabular}

veons

Relation of birth weight to infant mortality and Complex Adult-

Onset Disease Dover GJ. Trans Am Clin Climatol Assoc. 2009:120:199-207.

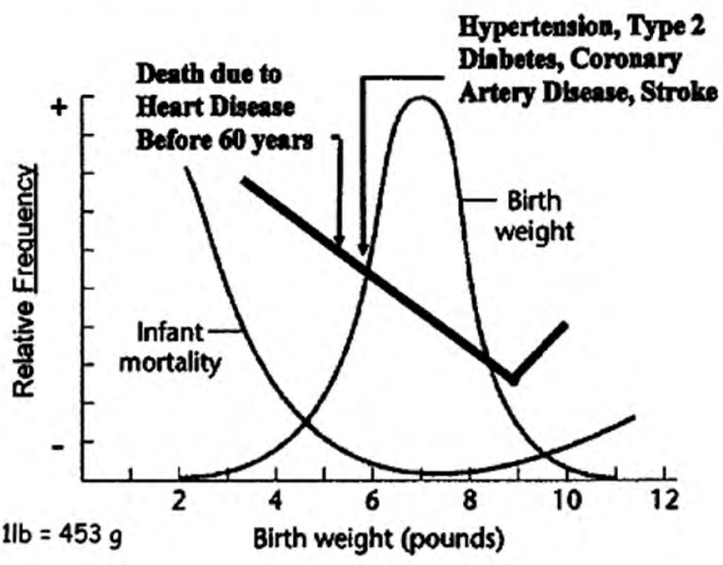

1 pound $=11 \mathrm{~b}=453 \mathrm{~g}$

irth weight (pounds)

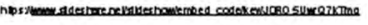

Figure 1. Birthweight with infant mortality and adult disease 
Fetal nutrition affects strongly to adult disease in later life. The Dutch famine at the end of the Second World War, 1944-1945 showed that: After 60 years, adults exposed to Dutch famine during gestation had been higher incidence of chronic diseases, as obesity, type 2 diabetes, aarterosclerosis, coronary heart disease, breast cancer, Alzheimer than others who were not exposed [17][18][19].

Acute maternal stress in pregnancy effects also to diseases of offspring in later life. A cohort study of $\mathbf{8 8 . 8 2 9}$ born in Jerusalem from 1964 to 1976, Malaspina D (2008) showed that adults who were born from the mothers in the $3^{\text {rd }}$ month of pregnancy during the Arab - Israel Six day War at 1967 had been high incidence of schizophrenia. The schizophrenia has been linked with intrauterine exposure to maternal stress due to bereavement, famine and major disorders [20].

\section{POSSIBLE MECHNISMS}

The most widely theory of development origin hypothesis is "programming". Programming is a concept whereby a stimulus or insult during a sensitive or critical period of growth and development long-term irreversible effects on structure, physiology, metabolism in tossues or organ system. Many mechanisms can explain the fetal origin of adult disease, but well - recognized mechanisms include alterd fetal nutrition, genetic-epigenetic links, fetal programming and glucocorticoid exposure.

\subsection{Altered fetal nutrition}

Fetal nutrition is a key regulator of fetal growth, as a nutritional programming influence [21]. Fetal undernutrition affects clearly to birthweight and adult disease in later life. Maternal rat, both global undernutrition and specific protein restriction result in reduced birhweight [22], hypertension [23], and impaires glucose tolerance 24] in offspring. Similar effects have been reported in guinea pig [25] and sheep [26].

In human pregnancy, both birthweight and placental weight were low due to undernutrition [27]. Imbalance of protein and carbohydrate intake during pregnancy has been associated with reduced birthweight and hypertension in offspring [28]. Micronutrients may also play an important role in programming of postnatal disease. India pregnancy women intake of green vegetables and fruit were associated with birth size and glucose tolerance in offspring [29] Higher calcium intake during pregnancy has been associated with hypotension in offsprings [30].

Fetal overnutrition may be related with posnatal disease. Infants of diabetic mothers also expeience fetal overnutrition, they are exposed to increased glucose and fatty acid in blood before birth, and increased risk of glucose intolerance and type 2 dibetes in later life [[31].

Alterd fetal nutrition may be lead to stimulate common programming in increasing risk of adult disease [31]. The following schema describes of altered fetal nutrition directly or indirectly leading to altered growth and maturation of various fetal organ systems influencing to disease in later life. 


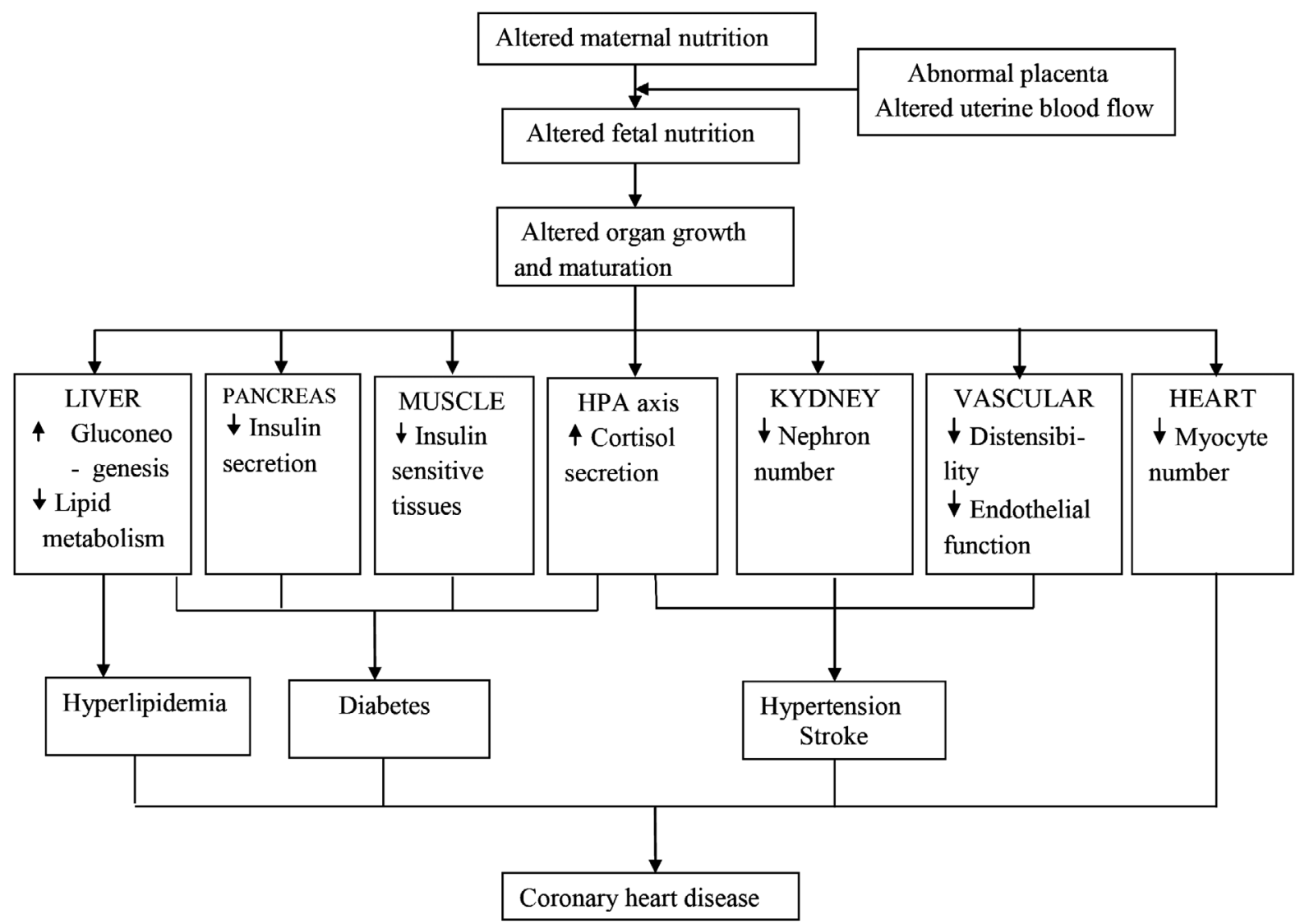

Figure 2. Altered fetal nutrition on growth and maturation of fetal organ systems and their links with adult disease

2.2. Genetic and Epigenetic links - Fetal programming

The relation between fetal growth and adult disease must ultimately involve changes in gene expression, which are very likely in involve epigenetic phenomena. During early embryogenesis, DNA undergoes demethylation and remethylation; some genes from maternal or paternal origin have been inactivation, that affect many genes regulating fetal and placental growth [33] Fetal nutrition is an important environment factor of DNA regulating, and also the source of methyl and acetyl affecting to methylation and acetylation of epigenetic mechanisms leading to phenotype changes and adult disease later (Cartin và cs., 2013). Intrauterine environment affects to epigenetic mechanism establishing fetal developmental genotype, fetal programming - early life programming, leading to programmed a large number of metabolic and phusiological genes influencing to health and adult chronic diseases [34]. 


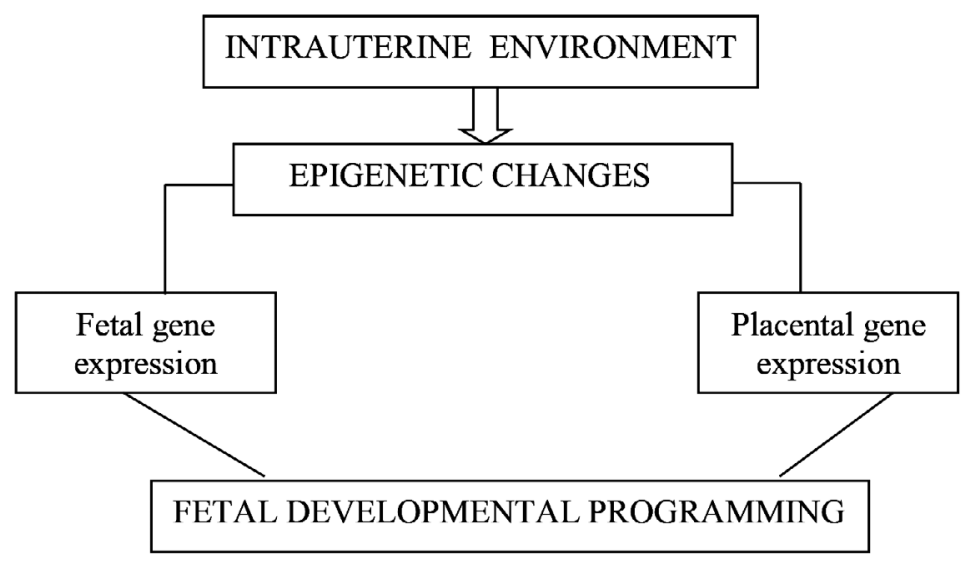

Figure 3. Effects of intrauterine environment and fetal developmental programming.

2.3. Thrifty phenotype hypothesis and Adaptive response

The "Thrifty phenotype" hypothesis first proposed by Hales and Barker suggested that adult insulin resistance and type 2 diabetes could result from the persistence of the fetal adaptive response in intrauterine hypoglycemia due to fetal undernutrition [35]. During periods of maternal undernutrition, the fetal reduces insulin secretion and increases insulin resistance, thus directing more glucose to the brain and heart, and less to insulin-dependent tissues such as skeletal muscles [36]. When nutrient is abundant in postnatal life, this pancreatic betacell defect and peripheral insulin resistance could then cause glucose intolerance and diabetes. This would explain why thin babies become overweight during childhood who are prone to developing type 2 diabetes in later life [37].

\subsection{Glucocorticoids}

Another mechanism by which adult cardiovascular and metabolic disease may be program-med in via expocure in excess glucocorticoids. This may be occur in utero if maternal glucocortioid level is elevated due to exogenous glucocorticoid administered; or if the placental barrier that protects the fetus from high level of maternal glucocorticoid is impaired. Intrauterine glucocorticoid exposure leads to reduce number of glucocorticoid receptors in the hypothalamus, resulting in impaired negative feedback and hence long-term up-regulation of hypothalamus- pituitary-adrenal axis after birth [38], contributing to increased blood pressure and glucose intolerance in offspring.

Rats given dexamethsone during pregnancy have reduced birthweight and increased blood pressure, glucose intolerance in adulthood [39]. Similar effects are seen in human pregnancy, babies born small to have higher plasma cortisol, lower activity of 11 betaHSD-2 (11 beta hydroxysteroid dehydrogenase-2) in placenta. Repeated administration of betamethasone or dexamethasone during pregnancy has been associated with reduced size at birth [40].

\subsection{Fetal insulin hypothesis}

Hatterley proposed that the relation between small size at birth with impaired glucose tolerance in adult can explain by inherited deficits in nsulin secretion or action [41]. Insulin is an important regulator of fetal growth, impaired insulin secretion would have impaired growth before birth and would have also impaired glucose tolerance in adulthood [42].

\subsection{Intergenerational effects}

Adverse events during pregnancy can affect not only the offspring of that pregnancy but also 
the next generation. It has long been recognized that birthweight of the mother is related to the birthweight of her children. Studies in Dutch hunger winter 1944-1945, women who were severely undernutrition during the first trimester of pregnancy gave birth to babies with normal average birthweight, but those babies themselves then went on to give birth to small babies in the next generation [43]. There are several possible explainations for these intergenerational effects on birthweight : (1) The humonal environment of the uterus of undernourished mothers may affect the developing reproductive tract of the fetus with reduced uterine and ovarian size, thereby reducing fetal growth of next generation [44]; (2) Any epigenetic changes at the genome may be passed on the second generation [45].

\subsection{Intergrated mechanism}

There are some possible mechanisms on explaining the fetal origin of adult disease. Some mechanisms can integrate in any individual to developing adult disease in later life. The following schema describes the integrating mechanism.

\section{Integrating mechanisms}

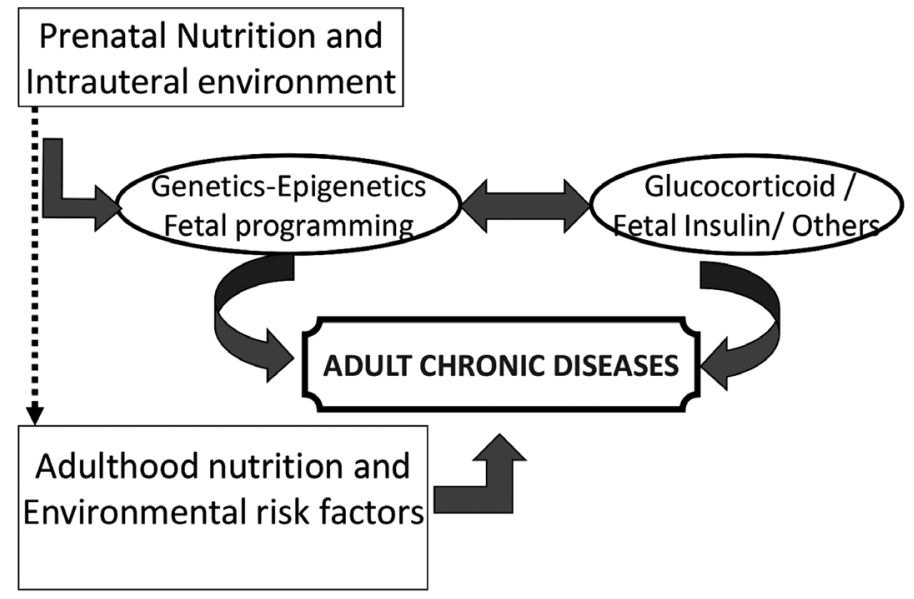

Figure 4. Intergrating mechanism

\section{CONCLUSIONS}

Fetal Origin of Adult Disease hypothesis is widely accepted. Large number of studies have provided evidence for that reduced size at birth, fetal undernutrition, also other adverse insults during pregnancy are related of adult onset chronic disease in later life. There are several possible mechanisms, the most widely accepted mechanisms are altered fetal nutrition, genetic-epigenetic links, fetal programming and glucocorticoid exposure. All risk factors of low birthweight eliminate and prenatal care, including mother, fetal and neonatal care, are crucial prevention of number adult chronic disease.

\section{REFERENCIES}

1.Barker DJ, Osmond C (1986). Infant mortality, childhood nutrition and ischaemic heart disease in England and Wales. Lancet, 1: 1077- 1081.

\section{Barker DJ, Winter FD, Osmond C, Margetts}

B, Simmonds SJ. (1989). Weight in infancy and death from ischaemic hear disease. Lancet; 2 : 577-580.

\section{Barker DJ, Osmmond C, Simmonds SJ, Wield}

GA. (1993). The relation of small circumference and thinness at birth to death from cardiovascular disaes in adult life. Br Med J ; 306 :422-426. 
4. Barker DJ. (1993). Fetal nutrition and cardiovascular disease in adult, Lancet; 341 : 938

5. Barker DJ and Hales CN. (2001) The thrifty phenotype hypothesis. Br Med Built; 60 : 5-20.

6. Gluckman (2004). Environmental Effects via Developmental Plasticity Types of Response to Early Environment; Science 305“ 1733.

7. Barker DJ. (1994). The foetal origins of adult disease. Fetal and Maternal Medicine Review: $671-680$.

8. Shakti Bhan Khamma, Kiranabala, Swasti, Kaushibi Dwivedeo (2007). Fetal Origin of Adult Disease. Science; V9, 4 : 206-211.

9. Christopher Lau, John MR, Desai M, Ross MG, (2011). Fetal Programming of Adult Disease. Implications for Prenatal Care. The American College of Obstetricians and Gynecologists, V117; 4 : 978 - 984.

10. Hendrina A, De Boo, Harding JE (2006). The Development Origins of Adult Disease (Barker) Hypothesis. Australian and New Zealand Journal of Obstetrics and Gynecology; 46 : 4 -14.

11. Barker DJ. (2007). The origins of the developmental origin theory. J. Inter Med.; 241: 412.

12. Phillips DIW (1996). Insulin resistance as a programmed response to fetal undernutrition. Diabetologia; 39 : 1119- 122.

13. Waterland RA, Garza C (1999). Potential mechanisms of metabolic imptinting that lead to chronic disease. Am J Clin Nutr; 69 : 179 -197.

14. Dover GJ (2009). Relation of birthweight to infant mortality and Complex Adult - Onset Disease Trans Am Clin Climatol Assoc 120: 199 - 207.

15. Pei CH (2010). Low birthweight and Lung Function in Adulthood: Retrospective Cohort Study in China 1948 - 1996. Pediatrics; 125: 899 - 905.

16. Thompson C. (2001). Bith weight and the risk of depressive dicorder in late life. $\mathrm{Br} J$ Psychiatry; 179 : 450 - 455.
17. Ravelli AC, van der Meulen JH, Osmmond C, Barker DJ, Bleker OP. (1999). Obesity at the age 50y in men and women exposed to famine prenatally. Am J Clin Nutr; 70 : 811-816.

18. Roseboom TJ, van der Meulen JH, Ravelli AC, Osmmond C, Barker DJ, Bleker OP. (2003). Perceived health of adults after prenatal exposure ti the Dutch famine. Pediatr Perinal Epidemiol; 17 : 391-397.

19. Painter RC, Roseboom TJ, Bleker OP, (2005). Prenatal exposure to the Dutch famine and disease in late life: an overview. Reprod Toxicol; $20: 345-352$.

20. Malaspina C. (2008), Acute maternal stress in pregnancy and schizophrenia in offspring : a cohort prospective study. BMJ Psychiatry; 8 : 76.

21. Harding JE. (2001). The nutritional basis of the foetal origins of adult disease. Int J Epidemiol; $30: 15-23$

22. Desai M, Crowther NJ, Lucas $A$, Hales CN. (1996). Organ-selective growth in the offspring of protein-restricted mothers. Br J Nutr; 76: 59 $-603$.

23. Woodal SM, Johnston RM, Breier BH, Gluckman PD. (1996). Chronic maternal undernutrition in the rat lead to delayed posnatal growth and elevated blood pressure of offspring, Pediatr Res; 40 : 438 - 443.

24. Ozanne SE, Hales CN. (1999). The longterm consequencies of intrauterine proteinmalnutrition for glucose metabolism. Proc Nutr Soc; $58 ; 615$ - 619.

25. Kind KL, Clifton PM, Grant PA. (2003), Effect of maternal feed restriction during pregnancy on glucose tolerance in the adult guinea pig. Am J Physiol; 284 : R140 - R152.

26. Gardner DS, Tingey K, Can Bon BW. (2005). Programming of glucoe-insulin metabolism in adult sheep after maternal undernutrition. Am J Phisiol; 289 : R947 - R954. 
27. Moore VM, Davies MJ, Willson KJ, Worsley A, Robinson JS. (2004). Dietary composition of pregnant women is related to size of the baby at birth. J Nutr; 134 : 1820 - 1826.

28. Shiell AW, Campell-Brown M, Haselden S, Robinson S, Godfrey KM, Barker DJ. (2001). High-meat, low- carbohydrate diet in pregnancy relation to adult blood pressure in offspring. Hypertension; 38: 1282 -1288.

29. Yajnik CS. (2004), Early life - origins of insulin resistance and type 2 diabetes in India and other Asian countries, J Nutr; 134 : 205 - 210.

30. Gillman MW, Rifas-Shiman SL, Kleinman KP, Rich Edwards JW, Lipshultz SE. (2004) Maternal calcium intake and offspring blood pressure. Circulation; 110 :1990 - 1995.

31. Sofngwi E, Boudou P, Mauvais-Jarvis $F$. (2003). Effect of a diabetic environment in utero on predisposition in type 2 diabetes. Lancet; 361: 1861 - 1865.

32. Buckley AT, Jaquiery AJ, Harding JE. (2005). Nutritional programming of adult disease. Cell Tissue Res :73-79.

33. Reik W, Dean W, Walter J. (2001). Epigenetic reprogramming in mammalian development. Science; 293 : 1089-1013.

34. Waterland RA, Jirtle RL. (2004) Early nutrition, epigenetic changes at transposons an imprinting genes, and enhanced susceptibility in adult chronic diseases. Nutrition; 20 : 63-68.

35. Hales CN, Barker DJ. (1992) Type 2 (non-insuline dependent) diabetes mellitus: the thrifty phenotype hypothesis. Diabetologia; 35: 695- 901.

36. Phillips DI. (1996): Inmsilinr resistance as a programmed response to foetal undernutrition. Diabetologia; 39 : 1119 - 1121.

37. Eriksson JG, Forsen T, Tuomilehto J, Osmmonds C, Barker DJ (2003) Early adiposity rebound in childhood and risk of Type 2 diabetes in adult life. Diabetologia; 46 : 190 - 194.
38. Seckl JR. (2004), Prenatl glucocorticoids and long-term programming. Eur J Endocrinol; 151 : U49 - U62.

39. Levitt NS, Lindsay RS, Holmes MC, Deskl JR. (1996), Dexamethasone in the last week of pregnancy attenuates hippocarpan glucocorticoid receptor gene expression and elevates blood pressure in the adult offspring in the rat. Euroendocrinology; 64 : 412 - 418.

40. Thorp JA, Jones PG, Knox E, Clark RH. (2002), Does antenatal corticoid therapy affect birth weight and head circumference. Obst Gyyneol: 99 : 102 -108.

41. Hatterley AT, Tooke JE. (1999). Yhe foetal insulin hypothesis: an alternative explanation of low birth weight with diabetes and vascular disease, Lancet; 353 : 1789 - 1792.

42. Day IN, Chen XH, Gaunt TR. (2004), Late life metabolic syndrome, early growth and common polymorphism in the growth hormone and placental lactogen gene cluster. Endocrinol Metab; 89 : 5569 - 5576.

43. Stein AD, Luney LH (2000), The relationship between maternal and offspring birth weight after maternal prenatal famine exposure the Dutch Famine. Birth Cohort Study. Hum Biol; 72: $641-651$.

44. Ibamez L, Potau N, Enriquez G, de Zegher F. (2000), Reduced uterine and ovarian size in adolescent girls born small for gestational age. Pediatr Res; 17 : 575 - 577.

45. Reik W, Santos F, Dean W. (2003), Mammalian epigenomic reprogramming the genomic for development and therapy. Theriogenology; $59: 21$ - 32. 